\title{
T3a Stage Finding
}

National Cancer Institute

\section{Source}

National Cancer Institute. T3a Stage Finding. NCI Thesaurus. Code C48729.

A general term that refers to a TNM finding of a primary tumor usually indicating that the cancer is locally invasive. The definition of T3a TNM finding depends on the specific type of cancer that it refers to; for example, for kidney cancer it refers to a primary tumor that grossly extends into the renal vein or its segmental (muscle containing) branches or the tumor invades perirenal and/or renal sinus fat but does not extends beyond Gerota's fascia; for cervical cancer it refers to a primary tumor that involves the lower third of vagina, without extension to pelvic wall; for liver cancer it refers to the presence of multiple tumors measuring more than $5 \mathrm{~cm}$ in greatest dimension. 